\title{
A disforia de gênero como síndrome cultural norte-americana
}

\author{
Rogério da Silva Paes Henriques' (iD 0000-0002-6777-1921 \\ André Filipe dos Santos Leite ${ }^{1}$ (iD) 0000-0003-2414-0676 \\ 'Universidade Federal de Sergipe, São Cristóvão, SE, Brasil. 49100-000 - \\ dps.ufs@gmail.com
}

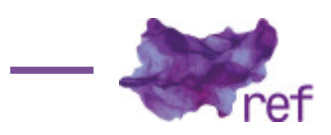

Resumo: O diagnóstico "disforia de gênero", proposto pela quinta edição do Manual Diagnóstico e Estatístico de Transtornos Mentais (DSM-5), é apresentado como uma "síndrome cultural" norte-americana, ilustrando a tendência expansionista da American Psychiatric Association (APA) em arregimentar as experiências de trânsito de gênero que escapem à matriz de inteligibilidade centrada em torno do masculino/feminino. A esse diagnóstico, forjado pelo pensamento binário estadunidense, nos moldes da chamada disease mongering, opõe-se a experiência da travesti brasileira como alteridade radical para com a matriz de inteligibilidade de gênero instituída.

Palavras-chave: disforia de gênero; síndrome cultural; DSM-5; Disease mongering; travesti brasileira.

\section{Gender Dysphoria as a American Cultural Syndrome}

Abstract: The diagnosis "gender dysphoria", proposed by the fifth edition of the Diagnostic and Statistical Manual of Mental Disorders (DSM-5), is presented as a American "cultural syndrome". This illustrates the expansionist tendency of the American Psychiatric Association (APA) to regiment gender-based transit experiences that escape the matrix of intelligibility centered around the male / female. Against this diagnosis, forged by American binary thinking, in the mold of the so-called disease mongering, we oppose the experience of the Brazilian travesti as a radical alterity to the established gender intelligibility matrix. Keywords: Gender dysphoria; Cultural syndrome; DSM-5; Disease mongering; Brazilian travesti.

\section{Transamérica?}

Desde os antigos astrônomos gregos, o globo terrestre é dividido em um sistema de linhas imaginárias traçadas sobre sua superfície que tem por objetivo, através da intersecção entre as linhas verticais (os meridianos) e as linhas horizontais (os paralelos), localizar qualquer ponto na superfície da Terra. Para além desses acordos cartográficos, que permitem nossa orientação espacial - e mais recentemente também temporal, visto que os meridianos funcionam inclusive como fusos horários -, tais marcadores, especialmente Greenwich e Equador, carregam uma marcação simbólica não somente orientadora de bússolas, astrolábios e balestilhas, mas também norteadora de nossos próprios agenciamentos cotidianos. Basta que observemos como, em termos culturais, geopolíticos e econômicos, operamos com a ideia de hemisfério norte e sul/ocidental e oriental, colocando sempre os primeiros como superiores aos segundos.

Vale ressaltar que não é de agora que essa hierarquização entre norte/sul e ocidente/ oriente e seus produtos - colonialismo, orientalismo, imperialismo, etnocentrismo etc. - são objetos de diversas críticas oriundas dos estudos culturais, pós-estruturalistas, pós-coloniais e tantos outros. Tendo essas perspectivas teóricas como pano de fundo, pretendemos investigar neste trabalho o quanto a medicina, mais especificamente a psiquiatria norte-americana, atravessada por tais referentes hierarquizantes, funciona produzindo um conjunto de práticas que amplia a esfera da influência geopolítica dos Estados Unidos sobre o "resto" do mundo. Ou, mais propriamente, como o imperialismo cultural estadunidense "repousa sobre o poder de universalizar os particularismos 
ligados a uma tradição histórica singular, fazendo-os não se reconhecerem como tais"' (Pierre BOURDIEU; LOÏc WACQUANT, 1998, p. 109).

Assim como no século XIX várias questões filosóficas debatidas na Europa provinham de particularidades históricas próprias às universidades alemãs, atualmente diversas discussões intelectuais que se disseminam ao resto do mundo, aparentemente desvinculadas de qualquer regionalismo específico, referem-se aos particularismos da sociedade e dos meios universitários norte-americanos. Bourdieu e Wacquant (1998) sugerem que a ampla difusão de "teses com as quais discutimos, mas sobre as quais não discutimos" (p. 109), nos campos acadêmico e político mundiais, favorece a neutralização do contexto histórico que as originou e produz uma universalização aparente que fortalece o trabalho de teorização da nova doxa intelectual planetária num processo de "McDonaldização servil do pensamento".

Nesse sentido, vários temas recentemente aparecidos no cenário intelectual mundial são "produtos da pesquisa americana [...] conduzindo a uma espécie de despolitização principal dos problemas sociais e políticos, assim desembaraçados de qualquer referência a qualquer espécie de dominação" (BOURDIEU; WACQUANT, 1998, p. 111 1). Um exemplo ilustrativo encontra-se no debate acerca da "raça" e da "identidade". O modo arbitrário e reducionista pelo qual os norte-americanos assinalam a dicotomia entre brancos e negros está se disseminando em países onde os princípios de concepção e de divisão das diferenças "raciais" são completamente distintos. A incoerência desses "estudos colonizadores" fica em evidência quando se verifica a discrepância da concepção de "raça" entre os Estados Unidos e o Brasil, por exemplo. Enquanto os norte-americanos definem a "raça" unicamente através da análise da ascendência familiar, bastando o indivíduo possuir um ou vários parentes identificados como negros para ser também identificado sumariamente como tal, independentemente de quaisquer características físicas ou sociais, os brasileiros utilizam princípios mais plásticos para essa mesma definição. Os brasileiros levam em consideração, além das variações das tonalidades de cor da pele, outras características físicas como a textura dos cabelos, a forma dos lábios e do nariz, bem como a posição ocupada pelo indivíduo no espaço social, o que culmina na existência de um espectro (continuum) entre os dois extremos: brancos e negros. A inexistência de categorias intermediárias na lógica classificatória etnorracial estadunidense parece-nos próxima, em termos de uma gramática binário-normativa, da equivalente ausência de categorias intermediárias (entre o normal e o patológico) na lógica classificatória da American Psychiatric Association (APA). Esta se encontra materializada no Manual Diagnóstico e Estatístico de Transtornos Mentais, atualmente em sua quinta edição: DSM-5 (AMERICAN PSYCHIATRIC ASSOCIATION/APA, 2014).

O modelo dimensional em nosografia psiquiátrica é dinâmico, sendo o normal e o patológico os dois extremos de um espectro no qual se distribui quantitativamente o real da condição humana. Assim, por se constituir num continuum que varia do normal ao patológico, um enfoque nosográfico dimensional permite múltiplas possibilidades de nuances quantitativas, várias gradações entre os estados que se compreende como normal e patológico. Já o modelo categorial, que passou a embasar o DSM, a partir de sua terceira edição de 1980 vigorando até a versão atual, é estático, sendo o normal e o patológico determinados de modo binário por critérios qualitativos de inclusão e exclusão a categorias nosológicas predeterminadas. Tal modelo segue a lógica aristotélica da classe e do atributo, que substancializa identidades em categorias fixas (essências) - daí lan HACKING (2000) sugerir que o DSM classifica pessoas, e não propriamente doenças. Dessa forma, no modelo categorial bidimensional, a pessoa, se portadora dos atributos requisitados, inclui-se à tipologia proposta. A opção pela divisão do conjunto dos transtornos mentais em categorias ou tipos-ideais reflete a adesão do DSM à tese de que a patologia é mais fielmente representada dessa forma. Contudo, não há qualquer evidência científica que justifique a escolha pelo modelo categorial em psiquiatria. Um dos elaboradores da terceira edição do DSM, J. S. Saraus, afirmou que, depois de anos dedicados a contribuir com o desenvolvimento desse manual, fora para ele impossível não se dar conta de que, com frequência, os pacientes psiquiátricos não se encaixavam de maneira correta nas tipologias propostas, uma vez que eles descreviam experiências "intermediárias" em relação à definição dos sintomas (um pensamento delirante ou "quase" normal; uma alucinação ou um pensamento percebido de forma "muito intensa"), o que acarretava marcações frequentemente arbitrárias. A utilização desse manual para levantamento diagnóstico "mostrava como as pessoas 'reais' bem pouco se adaptavam às categorias psiquiátricas: emergia claramente um continuum entre diversos grupos diagnósticos, entre diversos grupos de sintomas e também entre manifestações sintomáticas e manifestações psicológicas normais" (apud Benedetto SARACENO, 1999, p. 89-90). Deve-se, portanto, buscar em outro lugar, que não na racionalidade científica, a adesão da APA ao modelo categorial.

O próprio DSM-5 assimila tal crítica quando afirma que "a aspiração histórica de se atingir homogeneidade diagnóstica a partir de uma subtipificação progressiva inserida em categorias de

\footnotetext{
${ }^{1}$ Todas as traduções de citações de textos estrangeiros são nossas.
} 
transtornos não é mais sensata" (APA, 2014, p. 12 [grifo nosso]). Contudo, conserva o "insensato" modelo categorial, ao menos até que a pretensa "evolução" científica abra alas para transformações nosográficas efetivas. Dessa forma, apregoa que "revisões contínuas do DSM-5 fazem com que ele se transforme em um 'documento vivo', adaptável a descobertas futuras em neurobiologia, genética e epidemiologia" (APA, 2014, p. 13 [grifo nosso]). Tal pretensão de "adaptação" específica a "futuras descobertas científicas" (APA, 2014, p. 17) exclui a interlocução com outras configurações diagnósticas já existentes, baseadas em modelos teóricos não biológico-estatísticos. O DSM-5 é explícito nesse sentido e procura se amalgamar no pretenso naturalismo biológico.

Percebe-se, assim, que tanto o sistema classificatório etnorracial quanto o sistema classificatório psiquiátrico norte-americanos apoiam-se no pensamento binário (e, por conseguinte, na caracterização tipológica rígida) como representante do que há talvez de mais típico da cultura estadunidense. Digamos que a ciência norte-americana é bastante enviesada/interessada e as manifestas pretensões globais de sua doxa acabam por universalizar, de modo latente, sua concepção de mundo particular. Desse modo, autores das mais diversas perspectivas teóricas (Atwood D. GAINES, 1992; Allan YOUNG, 1997; HACKING, 2000; Rogério P. HENRIQUES, 2015; Allen FRANCES, 2016) vêm denunciando que o DSM, para além de sua carapaça científica pretensamente neutra (ateórica e descritiva), refletiria os valores culturais dos Estados Unidos. Gaines (1992), um dos autores a inaugurar esse tipo de crítica, extraiu uma etnopsicologia subjacente a esse manual isolando uma noção positiva idealizada do eu: aquela de um "eu referencial", autocontrolado, cujas questões existenciais centrais se referem à autonomia, à individualização e ao desenvolvimento/crescimento pessoal; a psiquiatria norte-americana seria então uma etnopsiquiatria (na medida em que é porta-voz da "tradição protestante germânica do norte europeu" e de sua concepção de eu) e não, como sustenta a APA, produto de uma síntese científica supostamente trans-histórica e transcultural.

\section{Síndrome cultural}

O termo Culture-Bound Syndrome (CBS) foi cunhado pelo psiquiatra chinês P. M. Yap, em 1967, no intuito de agrupar conceitualmente as síndromes restritas a grupos ou culturas específicas numa rubrica geral. Passou a ser adotado no lugar de expressões como psicoses étnicas, neuroses étnicas, psicoses histéricas, exóticas ou atípicas e síndromes reativas à cultura. O DSM-4, de 1994, popularizou tal termo a partir de sua inclusão no Apêndice I - "Plano de Formulação Cultural e Glossário para Síndromes Ligadas à Cultura". O DSM-5, por sua vez, reagrupa em um capítulo específico a discussão em torno da "Formulação Cultural" do diagnóstico e manejo clínicos (APA, 2014, p. 749-759); e segue apresentando nos apêndices um "Glossário de Conceitos Culturais de Sofrimento" (APA, 2014, p. 833-837) que possui um quantitativo reduzido de categorias similares àquelas descritas na edição anterior.

Sugerimos que, ironicamente, a noção de "síndrome cultural" utilizada no DSM-5 para definir síndromes psicopatológicas, que afetariam sociedades e culturas específicas, poderia ser aplicada a praticamente todos os transtornos listados no próprio DSM-5. Ou seja, seriam os transtornos descritos no DSM-5 produtos da própria cultura estadunidense e vendidos sob o rótulo de universais, o que, em última instância, parece funcionar como o exemplo mais ilustrativo do projeto expansionista da APA, que dissemina seus particularismos como sendo algo universal. Essa noção de síndrome cultural que existe para designar síndromes atribuídas a culturas exóticas, bizarras, estranhas, queers... - ou seja, que existe para capturar e arregimentar os contextos culturais específicos no âmbito de seu projeto universalista e acaba, por fim, nos fornecendo a chave de leitura para a empreitada da APA, entendendo que a biomedicina ocidental não pode ser considerada simplesmente como uma expressão científica
de demarcações naturais, na medida em que a sua definição, e as práticas que dela derivam,
são cultural e historicamente específicas. [...] se considerarmos que as fronteiras da competência
e do profissionalismo médico emergem como resultado de processos históricos e sociopolíticos,
acaba por ser difícil defender que as suas categorias podem ser utilizadas universalmente para
conferir ordem e coerência às experiências e às emoções dos outros (Claudia PUSSETI, 2006, p.
6).

Isso nos faz questionar: em que medida as categorias que se pretendem universais no DSM não refletiriam as peculiaridades da cultura norte-americana na delimitação de seus problemas locais? Ressaltando que o DSM surgiu, em 1952, como alternativa à Classificação Internacional de Doenças (CID) da Organização Mundial de Saúde (OMS), justamente em função de uma demanda dos psiquiatras norte-americanos, que não reconheciam na CID os transtornos psiquiátricos específicos existentes em solo estadunidense. Após a guinada metodológica de 1980, que coincidiu com a sua terceira edição, o DSM se repaginou como "descritivo e ateórico" e assumiu suas pretensões universalistas, porém, os transtornos psiquiátricos específicos dos Estados Unidos não desapareceram dessa terceira edição tampouco das seguintes; quem quer que tenha 
um pingo de visão crítica e curiosidade em folhear as páginas do DSM-5 encontrará transtornos com forte apelo regionalista.

\section{Da identidade à disforia de gênero}

Um desses transtornos, que se pretende universal, e que contemporaneamente se encontra constantemente atravessado por debates cada vez mais afinados sobre sua validade epistemológica como patologia, é a categoria de "disforia de gênero". O "transtorno de identidade de gênero" da edição anterior, renomeado "disforia de gênero" no DSM-5, relaciona-se mais propriamente àquilo que vem sendo descrito como "experiências trans" (Berenice BENTO, 2006) e, desde que se aventou a realização da última atualização do DSM, um movimento internacional denominado Stop Trans Pathologization se organizou na tentativa de pressionar os editores do DSM-5 a retirar o então "transtorno da identidade de gênero" do manual (Berenice BENTO; Larissa PELÚCIO, 2012), a exemplo do que já havia acontecido com a homossexualidade.

Os grupos homossexuais organizados pressionaram a APA na ocasião da revisão que levaria à terceira edição do DSM para que a homossexualidade deixasse de ser considerada um "desvio sexual", o que acabou acontecendo em 1974, por determinação dos editores desse manual, após aprovação num plebiscito interno realizado pela APA. O futuro da homossexualidade ter sido definido por um consenso corporativo da APA explicitou o quanto esse até então "transtorno mental" possuía fronteiras cientificamente imprecisas, definidas pela "moral sexual 'civilizada"' (Sigmund FREUD, 1996), constituindo-se assim num alvo privilegiado de disputas políticas. Contudo, diferentemente do desfecho favorável ocorrido com a homossexualidade, as experiências trans continuariam inscritas como patologia nas linhas do DSM-5, rebatizadas como "disforia de gênero". Assim, a cultura estadunidense engendra um projeto expansionista articulado à universalização de seus particularismos, cuja categoria disforia de gênero do DSM-5 é o emblema.

No DSM-5, os critérios diagnósticos para a disforia de gênero são:

A. Incongruência acentuada entre o gênero experimentado/expresso e o gênero designado de uma pessoa, com duração de pelo menos seis meses, manifestada por no mínimo dois dos seguintes:

1. Incongruência acentuada entre o gênero experimentado/expresso e as características sexuais primárias e/ou secundárias...

2. Forte desejo de livrar-se das próprias características sexuais primárias e/ou secundárias em razão de incongruência acentuada com o gênero experimentado/expresso...

3. Forte desejo pelas características sexuais primárias e/ou secundárias do outro gênero.

4. Forte desejo de pertencer ao outro gênero (ou a algum gênero alternativo diferente do designado).

5. Forte desejo de ser tratado como o outro gênero (ou como algum gênero alternativo diferente do designado).

6. Forte convicção de ter os sentimentos e reações típicos do outro gênero (ou de algum gênero alternativo diferente do designado).

B. A condição está associada a sofrimento clinicamente significativo ou prejuízo no funcionamento social, profissional ou em outras áreas importantes da vida do indivíduo (APA, 2014, p. 452-453).

Uma originalidade advinda com o DSM-5 é o reconhecimento de outras modalidades alternativas de gênero (critérios A4, A5 e A6) para além da gramática normativa homem/mulher visto que a edição anterior se atinha a tal oposição binária de gênero. O reconhecimento da diversidade de gêneros de fato é uma conquista. O DSM, como sistema classificatório enviesado culturalmente (GAINES, 1992), e não "descritivo e ateórico" - como se declara - acompanha de perto as demandas ativistas trans, assimilando-as, na medida do possível, ao seu escopo teórico. Isso denota que os transtornos psiquiátricos são transitórios, possuindo fronteiras maleáveis que exigem certo grau de negociação pública em sua definição. Atualmente, uma rede social bem difundida, como o Facebook, permite a personalização das opções de gênero, infinitizando-as. Qualquer usuário dessa rede que queira pode criar para si, via neologismo, um gênero singular. $O$ viés cultural do manual norte-americano de psiquiatria permite-lhe seguir essa mesma perspectiva de explosão de gêneros, sob o rótulo "gênero alternativo".

Contudo, as maiores novidades surgidas com essa categoria dizem respeito à introdução da noção de "incongruência" e à sua redefinição como "problema clínico, e não como identidade por si própria" (APA, 2014, p. 452 [grifo nosso]). Ambas as novidades encontram-se condensadas no próprio termo disforia. Advindo do grego (dys; phérein), que significa literalmente "má condução", algo próximo de "incongruência", ${ }^{2}$ por sua vez, uma tentativa de objetivação da anterior "inadequação" identitária, por intermédio do descompasso evidenciável entre o gênero designado,

2 "Incongruência de gênero" será o termo utilizado pela OMS na CID-1 1, cujo lançamento está previsto para 2018 , isto é, a nosografia internacional continuará a seguir à risca os passos pioneiros da nosografia psiquiátrica estadunidense nesse quesito. 
atribuído civilmente, e a conduta de gênero manifesta. Patricia GHEROVICI (2017, p. 21) endossa a justificativa da APA e afirma que a alteração semântica de "transtorno da identidade de gênero" para "disforia de gênero" contribuiu para a diminuição da estigmatização. Para além do mero semanticismo em jogo, sugerimos que houve sutil, porém significativa alteração na definição dessa categoria. Assim, a disforia, lida como incongruência, tende a modificar efetivamente o procedimento diagnóstico, ampliando seu espectro patologizante e gerando o que Frances (2016) designa como "inflação diagnóstica". Vejamos.

O exame de uma "identidade" (noção psicológica) requer a escuta subjetiva e, em alguma medida, a legitimação do sujeito a ser diagnosticado acerca de sua própria condição - isso quando não implica mesmo o autodiagnóstico; já o exame de um "problema clínico" (noção médica), a rigor, prescinde dessa escuta subjetiva e legitimação do sujeito, centrando-se no olhar perscrutador do diagnosticador em busca da "incongruência" entre o gênero designado (esfera pública) e a sua expressão individual (esfera privada). Se o DSM-4 exigia, em tese, certa horizontalidade entre diagnosticador/diagnosticado e uma negociação entre ambos, intermediada pela fala na delimitação consensual de uma identidade de gênero; o DSM-5 tende a verticalizar tal relação, reduzida à observação objetivante pelo diagnosticador dos comportamentos que comprovam a incongruência do diagnosticado. Uma clínica da escuta subjetiva (ao menos em termos potenciais) tende a se reduzir, assim, a uma clínica do olhar objetivante.

Não à toa, o DSM-5 é o primeiro manual a listar à parte, em uma tabela própria, os critérios diagnósticos específicos para crianças (APA, 2014, p. 452), justamente o grupo etário desautorizado socialmente a falar por conta própria. Se a identidade não é mais o fundamento do diagnóstico, este pode se estender indiscriminadamente às fases do desenvolvimento humano nas quais a identidade ainda está em formação. O diagnóstico como rótulo identitário - que exige autonomia psicológica - escapa à infância, porém, como incongruência, a inclui. E tal incongruência como problema clínico na infância, segundo o DSM-5, envolve comportamentos desviantes para com os gêneros designados, evidenciando o funcionamento de regras sociais baseadas numa rígida gramática normativa binária de gênero, bem típica - ainda que não exclusiva - da cultura norteamericana.

Dessa forma, aquilo que foi expulso pela porta da frente com o reconhecimento dos gêneros alternativos, retorna sorrateiramente pela janela dos fundos: a gramática normativa binária de gênero. Talvez, o que esteja em jogo nessa preocupação médica com a detecção de uma disforia de gênero na infância seja a distopia de um modelo curativo biomédico, aplicado cada vez mais precocemente, e não a utopia de uma promoção de saúde. ${ }^{3}$ Lembrando que qualquer utopia da promoção de saúde infantil descamba em distopia quando se avizinha às práticas de vigilância e gestão dos riscos que Michel FOUCAULT (1999, p. 99) designou por "pedagogização do sexo na criança", um dos "grandes conjuntos estratégicos que desenvolvem dispositivos específicos de saber e poder a respeito do sexo".

\section{Disforia de gênero: made in USA?}

Examinando a definição do DSM-5 sobre a disforia de gênero, observamos que o que está em jogo nas suas características diagnósticas são marcações culturais específicas, as quais, preocupadas em preservar os contornos dos gêneros, tentam circunscrever tudo aquilo que lhes escapa nos termos de uma patologia. Tal patologização embasa projetos interventivos calcados nas tecnologias hormono-cirúrgicas para o "tratamento" desses estados. O empreendimento tecnocientífico biomédico norte-americano toma então as matizes de "terapêutica" e, não à toa, conhece sua franca expansão na atualidade. De acordo com dados do Ministério da Saúde/MS (Amanda COSTA; Diogo CAIXOTE, 2016), desde 2008, com a inclusão do processo transexualizador no SUS, até 2014 , o número de procedimentos hormono-cirúrgicos saltou mais de $3.000 \%$, enquanto os repasses do MS para o custeio desses procedimentos cresceu $832,5 \%$ no período. Essa forma de medicalização pode ser nomeada como Disease mongering, que consiste na expansão dos limites de "doenças tratáveis" para expandir mercados de produtos a elas direcionados (Ray MOYNIHAN; lona HEATH; David HENRY, 2002).

Com relação à disforia de gênero em crianças, o DSM-5 reproduz as caricaturas dos papéis de gênero masculino e feminino. Assim, os "meninos pré-puberais com disforia de gênero [...] preferem usar trajes de meninas ou de mulheres ou podem improvisar roupas com qualquer material disponível (p. ex., usar toalhas, aventais e xales como cabelos longos ou como saias)"; esses

\footnotetext{
${ }^{3}$ Nesse sentido, acreditamos que a realocação dessa categoria no capítulo "Condições relativas à saúde sexual" da CID-11, a ser efetivada, será pro forma, mera medida administrativa demagógica, sem impacto efetivo na despatologização. Pelo contrário, tende-se a ampliar seu espectro patologizante já que tal manual autorizará o diagnóstico após os 5 anos de idade. Ressaltamos que a gravidez, por exemplo, consta na CID como condição de saúde que inspira cuidados, mas na prática é tratada por muitos como patologia. A incongruência de gênero parece tomar caminho semelhante.
} 
meninos "podem desempenhar papéis femininos em brincadeiras (p. ex., brincar de 'mãe')" e com frequência preferem atividades lúdicas tradicionalmente femininas como "brincar de casinha, desenhar quadros femininos, assistir a programas de televisão ou vídeos com personagens femininos favoritos"; "bonecas estereotípicas femininas (p. ex., Barbie) geralmente são os brinquedos favoritos, e as meninas são as companheiras de brincadeira preferidas" (APA, 2014, p. 453-454). Meninas pré-puberais, por sua vez, apresentam o transtorno quando "preferem usar roupas e cortes de cabelo de meninos", sendo com frequência "percebidas como meninos por estranhos". "Com frequência, sua preferência é por esportes de contato, brincadeiras agressivas e competitivas, jogos tradicionalmente masculinos e ter meninos como pares". Às vezes, chegam até a se recusar "a urinar na posição sentada" (APA, 2014, p. 453).

O que observamos é que, quando o DSM-5 descreve uma possível disforia de gênero em crianças, em nada o manual está se referindo a "constantes sintomatológicas clinicamente observáveis"; antes disso, está endereçando suas atenções às normativas de gênero que exigem que indivíduos nascidos com determinada genitália representem uma performance específica, historicamente construída e culturalmente assimilada àquela genitália em questão (Daniela M. AMARAL, 2007). Tais normativas de gênero são alçadas pelo DSM-5 ao patamar de marcadores diagnósticos: a preferência por "brincar com a Barbie" ou por escolher "esportes de contato" tornase parte significativa dos critérios necessários e suficientes no DSM-5 para a confirmação, em crianças, desse diagnóstico altamente estigmatizante.

A existência de sujeitos "subversivos" para com as normativas de gênero - em sua exigência de uma equivalência forçada entre sexo biológico e expressão de gênero (BENTO, 2006) - parece de algum modo assustar a sociedade norte-americana; basta novamente observar que os critérios diagnósticos utilizados no delineamento da disforia de gênero se baseiam estritamente numa regulação moral das experiências de gênero, considerando aqueles que destoam do que é culturalmente preconizado como "normalidade" na experimentação/performatização dos gêneros, objetos da classificação psiquiátrica com vistas à retificação. A APA aparece como guardiã da ordem instituída, legislando em prol das normativas de gênero, numa espécie de macarthismo psiquiátrico: os "subversivos" devem ser, cada vez mais precocemente, identificados, regulados, gerenciados, normatizados e "curados".

São as tecnologias cirúrgicas e os procedimentos endocrinológicos a "terapêutica" de escolha nesses casos, ao menos quando se trata de adolescentes e adultos. Hormônios, próteses e intervenções invasivas são elementos então arregimentados para a encenação de uma performance de gênero específica. O acionamento desses dispositivos tecnológicos como cirurgias de redesignação sexual (CRS), implantes de próteses mamárias e uso de fármacos hormonais como tratamento coincide justamente com um avanço dessas áreas no cenário norte-americano (Bernice L. HAUSMAN, 1995). Torna-se possível, desse modo, transitar de um gênero a outro, desde que preservada a sua gramática normativa binária; inverter o sexo designado no nascimento por intermédio da transformação corporal atrelada à tecnociência biomédica, garantidora da equivalência forçada entre o fenótipo sexual e a expressão de gênero - parece ser uma das poucas formas de transição aceitas na cultura norte-americana; assim, os "disfóricos" norteamericanos são construídos como consumidores de bens e de serviços biomédicos, nos termos da Disease mongering, sendo a transição de gênero similar a um processo industrial como linha de montagem. Nesse sentido, "o transexual define-se por uma demanda que não é mais possível sabermos em que medida é fabricada por sua própria oferta" (Simone PERELSON, 201 1, p. 4). A disforia de gênero mostra-se, assim, a solução de compromisso entre a construção corporativa da APA de um transtorno tratável e a construção social das demandas trans pelo direito de acessibilidade ao tratamento. Daí talvez o principal motivo da longevidade do DSM: sua capacidade de assimilação das críticas que lhe são direcionadas e das demandas sociais a ele formuladas, ao menos em parte.

Recentemente, os chamados Disabilty Studies (Paula GAUDENZI; Francisco ORTEGA, 2016) vêm questionando a noção de "deficiência" como algo individualizado e localizado nos "deficientes" (modelo médico). Afinal, a deficiência só existiria porque a sociedade não seria capaz de acolher as diferenças; assim, só existiria "deficiência física", por exemplo, em função da carência de mobilidade urbana (modelo social). A solução para a deficiência física seria intervir no deficiente via tecnociência biomédica (com o uso de exoesqueletos ou similares), assumindose como desvio a ser ortopedicamente corrigido? Ou seria intervir no ambiente social no sentido da construção de espaços arquitetônicos e urbanísticos mais acessíveis e democráticos, assumindose como diferença a ser acolhida? Em termos gerais, dever-se-ia adequar os "desviantes" à norma estatística (saudável?) ou fazer com que a coletividade acolha as suas diferenças, incluindo aí o "abjeto"? O atual empuxo à tecnociência biomédica que recai individualmente sobre os corpos abjetos parece reforçar o caráter supostamente patológico das experiências trans, em um processo de captura ao instituído. Nesse sentido, o DSM-5 introduz como critério de inclusão à disforia de gênero a ênfase no "sofrimento" (critério D), muito embora não analise se este seria expressão do 
patológico (fator endógeno) ou se seria efeito da patologização (fator exógeno). A questão é que o sofrimento, enfatizado de forma acrítica, acaba servindo como álibi à patologização.

\section{A travesti brasileira}

A disforia de gênero é apresentada no DSM-5 como "diagnóstico global" (APA, 2014, p. 451), em sua tentativa de englobar ao máximo as experiências de trânsito de gênero existentes no globo terrestre. Até que ponto uma categoria surgida nas gender clinics estadunidenses, na condição de resposta anglo-saxã à problemática do gênero - como nos mostra Arnaud ALESSANDRIN (2014, p. 3) - pode se estender a outros contextos culturais? Henry FRIGNET (2002, p. 121) relata como um grupo de etnólogos em missão na Birmânia ensinava os accault - travestis conforme uma tradição birmanesa - a demandar da ciência a cirurgia de redesignação sexual (CRS), a despeito de qualquer contextualização cultural.

Parece-nos ainda que o argumento de que a categoria de disforia de gênero é uma produção específica do pensamento binário norte-americano condizente com o empuxo à biotecnologia que sustenta seu modelo biomédico flexineriano - ou, dito de outro modo, que a disforia de gênero funciona como uma síndrome cultural estadunidense - se reafirma quando observamos em diversas partes do mundo a existência de outras experiências de trânsito entre os gêneros que são reguladas por diferentes códigos culturais e escapam à tentativa de captura do DSM-5. Assim, ressaltamos a diversidade das experiências trans existentes mundo afora: as travestis do Brasil, as hijras da Índia, as muxes do México, as mahu da Polinésia, as fakaleiti de Tonga, as fa'afafine de Samoa (Letícia LANZ, 2014) e tantas outras experiências de trânsito entre os gêneros que não se reduzem a isso que o DSM-5 designa como disforia de gênero.

Quando aportam em outros solos, seja a oeste do meridiano de Greenwich, seja ao sul da linha do Equador, essas outras experiências de trânsito dos gêneros oferecem diferentes inflexões existenciais. Nesse sentido, tomando brevemente como exemplo a experiência da travesti brasileira, sustentamos que essa modalidade particular de trânsito de gênero não necessariamente se subsume àquilo que o DSM-5 tenta descrever como disforia de gênero, evidenciando que muito pouco de universal tem esta última categoria.

O DSM-5 afirma que os portadores de disforia de gênero "podem encontrar outras maneiras de solucionar a incongruência entre o gênero experimentado/expresso e o gênero designado [...] sem procurar tratamento médico para alterar as características corporais" (APA, 2014, p. 454 [grifo nosso]), o que poderia sugerir que as travestis brasileiras se incluiriam nessa categoria, haja vista sua relativa autonomia com relação à demanda por tratamento médico nos termos da Disease mongering. Parece-nos, todavia, que essa modalidade de trânsito de gênero escapa a tal pretensa captura, pois não se enquadra ao que o próprio manual assinala ser o marcador diagnóstico indispensável de disforia, que fizemos questão de destacar no trecho citado anteriormente: "a incongruência entre o gênero experimentado/expresso e o gênero designado".

Desse modo, o que faria com que as experiências travestis definitivamente não se enquadrassem na categoria de disforia de gênero seria, sobretudo, a flagrante ausência dessa incongruência entre o gênero experimentado/expresso e designado, aspecto constatado por extensas etnografias sobre as travestis brasileiras (Hugo DENIZART, 1997; William PERES, 2005; Marcos Renato BENEDETTI, 2005; Larissa PELÚCIO, 2009). Tais estudos apontam o quanto a relação dessas pessoas com sua corporeidade não passa necessariamente pela ideia de "incongruência", mesmo que outros critérios diagnósticos vicinais para a disforia de gênero sejam de algum modo atendidos, especialmente os que se referem às alterações das características sexuais secundárias.

Outra possível tentativa de redução da experiência de trânsito de gênero da travesti brasileira à disforia de gênero é quando o DSM-5 assinala que "o equivalente à disforia de gênero foi também relatado em pessoas que vivem em culturas com outras categorias de gênero institucionalizadas além do masculino e feminino" (APA, 2014, p. 458). Contudo, o manual não deixa de ponderar que "não está claro se, no caso desses indivíduos, os critérios diagnósticos de disforia de gênero seriam preenchidos" (APA, 2014, p. 458 [grifo nosso]). É justamente em torno dessa falta de clareza confessada pelo DSM que pretendemos operar com os argumentos aqui desenvolvidos.

Se a categoria travesti, como experiência eminentemente tupiniquim restrita aos tristes trópicos, parece escapar dos meandros classificatórios da categoria de disforia de gênero, parece que o projeto expansionista da psiquiatria norte-americana tenta apreendê-la - como tantas outras experiências locais - em outro contexto: quando, dentro do grupo dos "transtornos parafílicos", - DSM-5 descreve uma categoria denominada "transtorno transvéstico", definida como uma "excitação sexual recorrente e intensa resultante de vestir-se como o sexo oposto (cross-dressing),

${ }^{4}$ Como eixo norteador dessa suposta incongruência, o DSM-5 aponta a negação e ojeriza que todos os sujeitos com disforia de gênero teriam dos seus próprios genitais, o que não acontece com as travestis, que nos estudos citados não relatam essa necessidade de alteração de suas genitálias externas. 
conforme manifestado por fantasias, impulsos ou comportamentos" (APA, 2014, p. 703), que difere da categoria de disforia de gênero devido à ausência de incongruência entre o gênero sentido/ designado e à ausência de desejo de alterações corporais/morfológicas. Contudo, não nos parece ainda assim que essa categoria do DSM consiga apreender a figura das travestis, tendo em vista que tais sujeitos recorrem a algumas alterações corporais, investindo na construção do feminino por meio do uso de silicone industrial e a administração de hormônios femininos, o que supostamente invalidaria sua adstrição ao transtorno transvéstico.

Assim, o que observamos é que, em um contexto propriamente brasileiro, as travestis encenam um tipo específico de experiência de trânsito de gênero que escapa aos limites daquilo que nossa cultura ocidental, marcadamente euroamericana, entende como masculino e feminino. Quando as travestis procuram marcar em seus corpos, a priori biologicamente masculinos, com signos do feminino mantendo, entretanto, alguns caracteres sexuais primários com os quais convivem sem grandes dilemas (DENIZART, 1997; PELÚCIO, 2009), percebemos o quanto essa ideia de "má condução" dos gêneros é um fenômeno marcadamente produzido num contexto norteamericano de rígidas fronteiras entre o masculino e o feminino. Mesmo que sem o desejo de alteração de suas genitálias, as travestis, a partir de uma apropriação subversiva de diversas técnicas protéticas, constroem seus corpos como femininos, seja por meio da ingestão de hormônios, seja se valendo do saber de outras travestis chamadas de "bombadeiras", que injetam silicone industrial naquelas que assim almejam. Essa "hibridização" do corpo, esse "monstro: meio masculino, meio feminino" (Jorge LEITE Jr., 2012), se torna inapreensível para a cultura norteamericana, já que nossos vizinhos de cima funcionam com base naquilo que Judith BUTLER (2012) destacava como matriz de inteligibilidade dos gêneros, ou seja, a necessidade de uma suposta coerência e continuidade entre sexo, gênero, prática sexual e desejo.

Esse tensionamento evidencia o quanto experiências profundamente locais, como as das travestis no Brasil, não podem ser marcadas sob a insígnia de uma categoria pretensamente universal calcada nos sistemas de raciocínio ocidentais e setentrionais. Tal "dis-posição" só denuncia o projeto expansionista da psiquiatria norte-americana de totalização do mundo em suas inscrições, um exercício que aponta para como essa categoria de disforia de gênero, descrita pelo DSM-5, funciona como uma síndrome cultural norte-americana.

\section{Considerações finais}

De algum modo, o que sugerimos neste trabalho tem a chancela do próprio DSM-5, que

reconhece que todas as formas de sofrimento são moldadas localmente, incluindo os transtornos do DSM. De acordo com essa perspectiva, muitos diagnósticos do DSM podem ser entendidos como protótipos operacionalizados que começaram como síndromes culturais e se tornaram amplamente aceitos como consequência de sua utilidade para a clínica e para a pesquisa (APA, 2014, p. 758).

Questionamos então se os critérios necessários e suficientes para que uma síndrome cultural torne-se um transtorno específico codificado no DSM (como ocorreu com a disforia de gênero) seriam tão somente a sua aceitabilidade e utilidade. Se sim, o DSM parece endossar o "anarquismo epistemológico" de Paul FEYERABEND (1977), assumindo-se como uma retórica mais convincente do que suas concorrentes. Nesse caso, pressupor-se-ia que a gramática biomédica, por gerar certo consenso utilitário e ter projeção global, seria mais válida do que as demais etnogramáticas de cunho local. Não à toa, o DSM-5 afirma que "diferenças culturais clinicamente importantes com frequência envolvem explicações ou experiência de sofrimento em vez de configurações de sintomas culturalmente distintivas" (APA, 2014, p. 758 [grifo nosso]). Sigamos tal raciocínio: se essa discussão sobre as síndromes culturais se resume a uma confusão babélica em função do modo pelo qual cada cultura expressa/experiencia o sofrimento, dentro em breve, com o desenvolvimento das apropriadas traduções, não haverá mais síndromes culturais, sendo todas elas capturadas pela gramática (útil e consensual) da biomedicina. As cartas estão na mesa. O projeto expansionista da APA nunca foi tão desnudado e a céu aberto. Cabe agora aos jogadores se posicionarem para a partida.

\section{Referências}

ALESSANDRIN, Arnaud. 'Du 'transsexualisme' à la 'dysphorie de genre': ce que le DSM fait des variances de genre". Socio-logos, n. 9, abr. 2014. Disponível em http://socio-logos.revues.org/2837. Acesso em 27/04/2018.

AMARAL, Daniela M. A psiquiatrização da transexualidade: análise dos efeitos do diagnóstico de transtorno de identidade de gênero nas práticas de saúde. 2007. Dissertação (Mestrado em Saúde Coletiva) - Programa de Pós-Graduação em Saúde Coletiva, Instituto de Medicina Social da Universidade do Estado do Rio de Janeiro, RJ, Brasil. 
AMERICAN PSYCHIATRY ASSOCIATION - APA. Manual Diagnóstico e Estatístico de Transtornos Mentais: DSM-5. Porto Alegre: Artmed, 2014.

BENEDETTI, Marcos Renato. Toda feita: o corpo e o gênero das travestis. Rio de Janeiro: Garamond, 2005.

BENTO, Berenice. A reinvenção do corpo: sexualidade e gênero na experiência transexual. Rio de Janeiro: Garamond, 2006.

BENTO, Berenice; PELÚCIO, Larissa. "Despatologização do gênero: a politização das identidades abjetas". Revista Estudos Feministas, Florianópolis, v. 20, n. 2, p. 559-568, maio/ago. 2012. Disponível em http://dx.doi.org/10.1590/S0104-026X201200020001 7. Acesso em 27/04/2018.

BOURDIEU, Pierre; WACQUANT, Loïc. "Sur les ruses de la raison impérialiste". In: BOURDIEU, Pierre (Dir.). Les ruses de la raison impérialiste. Actes de la Recherche en Sciences Sociales. Paris: Seuil, 1998. p. 109-1 18. Disponível em https://doi.org/10.3406/arss. 1998.3250. Acesso em 27/04/2018.

BUTLER, Judith. Problemas de gênero: feminismo e subversão da identidade. Rio de Janeiro: Civilização Brasileira, 2012.

COSTA, Amanda; CAIXOTE, Diogo. "Ministério lança campanha voltada à saúde da população trans". Portal do Ministério da Saúde, 27/01/2016. Disponível em http://portalms.saude.gov.br/ noticias/agencia-saude/21893-ministerio-lanca-campanha-voltada-a-saude-da-populacaotrans. Acesso em 02/05/2018.

DENIZART, Hugo. Engenharia erótica: travestis no Rio de Janeiro. Rio de Janeiro: Jorge Zahar, 1997.

FEYERABEND, Paul. Contra o método. Rio de Janeiro: Francisco Alves, 1977.

FOUCAULT, Michel. História da sexualidade I: A vontade de saber. 13. ed. Rio de Janeiro: Graal, 1999.

FRANCES, Allen. Voltando ao normal: como o excesso de diagnósticos e a medicalização da vida estão acabando com a nossa sanidade e o que pode ser feito para retomarmos o controle. Rio de Janeiro: Versal, 2016.

FREUD, Sigmund. "Moral sexual 'civilizada' e doença nervosa moderna". In: FREUD, Sigmund. Obras psicológicas completas de Sigmund Freud: edição standard brasileira. v. IX. Rio de Janeiro: Imago, 1996. p. 167-186.

FRIGNET, Henry. O transexualismo. Rio de Janeiro: Companhia de Freud, 2002.

GAINES, Atwood D. "From DSM-I to DSM-III-R; Voices of Self, Mastery and the Other: A Cultural Constructivist Reading of U. S. Psychiatric Classification". Social Science and Medicine, Cambridge, v. 35, n. 1, p. 03-24, 1992.

GAUDENZI, Paula; ORTEGA, Francisco. "Problematizando o conceito de deficiência a partir das noções de autonomia e normalidade". Ciência \& Saúde Coletiva, v. 21, n. 10, out. 2016. Disponível em http://www.cienciaesaudecoletiva.com.br/artigos/problematizando-o-conceito-de-deficienciaa-partir-das-nocoes-de-autonomia-e-normalidade/15811. Acesso em 04/05/2018.

GHEROVICl, Patricia. Transgender Psychoanalysis: A Lacanian Perspective on Sexual Difference. New York: Routledge, 2017.

HACKING, Ian. Múltipla personalidade e as ciências da memória. Rio de Janeiro: José Olympio, 2000.

HAUSMAN, Bernice L. Changing Sex: Transsexualism, Thechnology and the Idea of Gender. Durham: Duke University Press, 1995.

HENRIQUES, Rogério P. A psiquiatria do DSM: pílulas para que te quero. São Cristóvão: EDUFS, 2015. Disponível em https://www.academia.edu/30598398/A_Psiquiatria_do_DSM_p\%C3\%ADlulas_para _que_te_quero. Acesso em 27/04/2018.

LANZ, Letícia. O corpo da roupa: a pessoa transgênera entre a transgressão e a conformidade com as normas de gênero. 2014. Dissertação (Mestrado em Sociologia) - Programa de PósGraduação em Sociologia, Universidade Federal do Paraná, Curitiba/PR, Brasil. 
LEITE Jr., Jorge. "Transitar para onde? Monstruosidade, (des)patologização, (in)segurança social e identidades transgêneras". Revista Estudos Feministas, Florianópolis, v. 20, n. 2, p. 559-568, maio/ ago. 2012. Disponível em http://dx.doi.org/10.1590/S0104-026X2012000200016. Acesso em 27/ $04 / 2018$.

MOYNIHAN, Ray; HEATH, Iona; HENRY, David. "Selling Sickness: The Pharmaceutical Industry and Disease Mongering". BMJ, v. 324, n. 7342, p. 886-891, abr. 2002. Disponível em https:// www.ncbi.nlm.nih.gov/pmc/articles/PMC1122833/. Acesso em 27/04/2018.

PELÚCIO, Larissa. Abjeção e desejo: uma etnografia travesti sobre o modelo preventivo da AIDS. São Paulo: Annablume, 2009.

PERELSON, Simone. "Transexualismo: uma questão do nosso tempo e para o nosso tempo". Rev. Epos, Rio de Janeiro, v. 2, n. 2, dez. 2011 . Disponível em http://pepsic.bvsalud.org/pdf/epos/v2n2/ 04.pdf. Acesso em 27/04/2018.

PERES, William. Subjetividade das travestis brasileiras: da vulnerabilidade dos estigmas à construção da cidadania. 2005. Tese (Doutorado em Saúde Coletiva) - Programa de Pós-Graduação em Saúde Coletiva, Instituto de Medicina Social da Universidade do Estado do Rio de Janeiro, RJ, Brasil.

PUSSETTI, Claudia. "A patologização da diversidade: uma reflexão antropológica sobre a noção de Culture-Bound Syndrome". Etnográfica, Lisboa, v. 10, n. 1, p. 05-40, 2006. Disponível em http:/ /www.scielo.mec.pt/pdf/etn/v10n1/v10n1a01.pdf. Acesso em 27/04/2018.

SARACENO, Benedetto. Libertando identidades: da reabilitação psicossocial à cidadania possível. Belo Horizonte/Rio de Janeiro: Te Corá Editora/Instituto Franco Basaglia, 1999.

YOUNG, Allan. The Harmony of Illusions: Inventing Post-Traumatic Stress Disorder. New Jersey: Princeton University Press, 1997.

Rogério da Silva Paes Henriques (ruggerosph@gmail.com) é psicólogo; psicanalista de orientação lacaniana; mestre e doutor em Saúde Coletiva (Instituto de Medicina Social, Universidade do Estado do Rio de Janeiro); pós-doutor em Teoria Psicanalítica (Universidade Federal do Rio de Janeiro); pós-doutor em Psicologia (Universidade Federal Fluminense). Professor Associado do Departamento de Psicologia (Universidade Federal de Sergipe).

André Filipe dos Santos Leite (andrefsleite@yahoo.com.br) é médico (Universidade Federal de Sergipe) com Pós-Graduação em Psiquiatria (Universidade Estácio de Sá). Mestrando em Cinema e Narrativas Sociais (Universidade Federal de Sergipe).

\section{COMO CITAR ESSE ARTIGO DE ACORDO COM AS NORMAS DA REVISTA}

HENRIQUES, Rogério da Silva Paes; LEITE, André Filipe dos Santos. "A disforia de gênero como síndrome cultural norte-americana". Revista Estudos Feministas, Florianópolis, v. 27, n. 3, e56662, 2019.

\section{CONTRIBUIÇÃO DE AUTORIA}

Rogério da Silva Paes Henriques: a contribuição preponderante do autor se deu na análise da disforia de gênero na quinta edição do Manual Diagnóstico e Estatístico de Transtornos Mentais (DSM-5), bem como na análise deste manual como artefato cultural.

André Filipe dos Santos Leite: a contribuição preponderante do autor se deu na análise da literatura sócio-antropológica acerca da travesti brasileira.

\section{FINANCIAMENTO}

Trabalho subvencionado com bolsa de pesquisa da Coordenação de Pesquisa (COPES) da Universidade Federal de Sergipe.

\section{CONSENTIMENTO DE USO DE IMAGEM}

Não se aplica 
APROVAÇÃO DE COMITÊ DE ÉTICA EM PESQUISA

Não se aplica

\section{CONFLITO DE INTERESSES}

Não se aplica

\section{LICENÇA DE USO}

Este artigo está licenciado sob a Licença Creative Commons CC-BY International. Com essa licença você pode compartilhar, adaptar, criar para qualquer fim, desde que atribua a autoria da obra.

\section{HISTÓRICO}

Recebido em 05/05/2018

Aprovado em 09/10/2018 